$\left.\begin{array}{c}\text { Kalpa Publications in Engineering } \\ \text { Volume 3, 2020, Pages 19-25 } \\ \text { Proceedings of International Sym- } \\ \text { posium on Applied Science 2019 }\end{array}\right)$ Kalpel

\title{
Healing the third degree thermal burn in mice by Dielectric Barrier Discharge plasma (DBD plasma): comparison and Evaluation of area, burn wound healing time, burn skin temperature
}

\author{
Thi Minh Hien $\mathrm{Ngo}^{1, *}$, Tuyet Nhi $\mathrm{Do}^{2}$, Quoc Duy Nam Nguyen ${ }^{2}$, Duy \\ Phuong Nguyen ${ }^{1}$, Nguyen Ngan Ha Lam ${ }^{1}$, Quang Linh Huynh ${ }^{1}$ \\ ${ }^{1}$ Ho Chi Minh University of Technology1Ho Chi Minh University of Technology \\ ${ }^{2}$ National Cheng Kung University \\ nmhien@hcmut.edu.vn
}

\begin{abstract}
Burns are one of the most devastating conditions encountered in medicine. This injury is in skin or other tissues, caused by heat-cold, electricity or chemicals [1,2]. There are lots of methods to treat burns and each method has its own advantages, such as medicine, dressing, low-level laser, plasma, skin graft surgery... [3].

This study experimented with the 3rd degree burn model in mice by heat, treating by DBD plasma, is a non-invasive treatment and using clinical diagnostic methods by (1) normal image, (2) thermal image, (3) HE staining. Aim of this research is evaluation and comparison the area, temperature and wound healing time of non-invasive treatment with DBD plasma and nontreatment. After 3-week experiment, using diagnostic methods and analysis tools have demonstrated that the 3rd thermal burn wound healing of plasma treatment recovers faster than non-treatment about: (1) Burn wound surface shrinkage rate is higher: $~ 5 \%$; (2) Healing time is faster: 2-3 days; (3) The average temperature of the burn wound is lower: $1-2 \mathrm{oC}$. Therefore, DBD plasma is a potential treatment in burns wound and wound healing in the future. Keywords: DBD plasma, burn wound, healing wound
\end{abstract}

\section{Introduction}

Burn wound reaches the fourth place in all wound across the world. The proportion of people who need health care for being burn was 11 million people and this shows a completely different Picture that the figures for HIV and Tuberculosis were lower, in 2004. It is true that $90 \%$ death of burn happened 
in developing coutries ( has low per capita income) which main reasons such as laking of knowledge, skills about fire protection [4.5].

In America, the figure for people who find the treatment of burn is a half of million people and nearly $10 \%$ of which having to go to the hospital $[4,5]$. Burn not only makes the metabolism changed but also does it make the wound became inflammation and had complication. Moreover, infection is a major killer, accounts for $61 \%$ of all death [5].

In Viet Nam, the number of patients who suffer from burn is approximately a million people ( $1 \%$ of population) per year. In nowadays, thanks to the good fire protection, the number of patients of burn decreases significantly. Specially, the percentage of people who have side - effects by burn shows the dramatic change because the doctors do well about emergency treatment as well as function rehabilitation [6].

In this day and age, there are many methods and researchs are discovered for treating burn wound, with the purpose of finding the best treatment which means that it can minimize the complications and decrese the death ratio.

\section{Material and Methods}

\section{Object of study}

Male lab mice race BALB/C. The study choose mice by following reasons:

They have the same skin structure as human. Life cycle is short, gaving brith many babies, having a huge number which means that it is suitable for doing research and experiment. It is easy to breed, cheap price, do not have any conditions about cages and food. They have fast transformation so people find it easy to collect data during the experiment.

Source: INSTITUTE OF DRUG QUALITY CONTROL HO CHI MINH CITY

Average weight: $25 \mathrm{~g}-26 \mathrm{~g}$

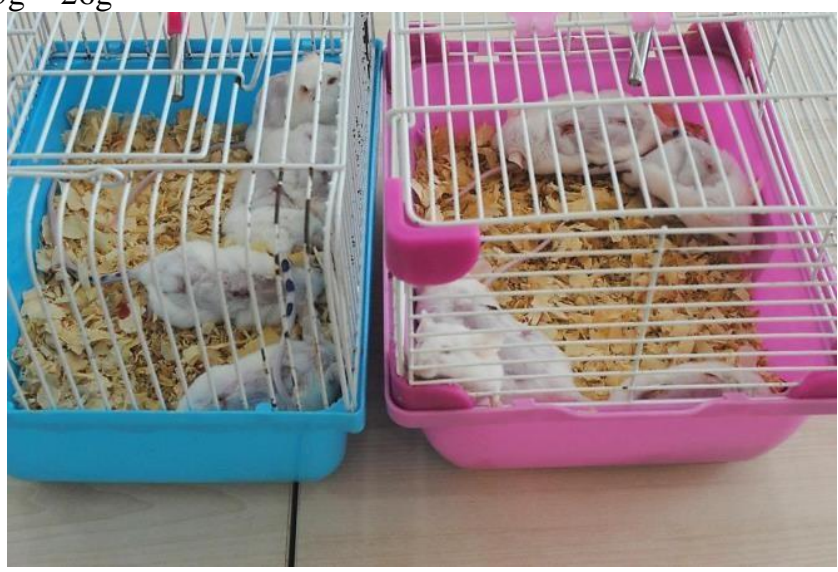

Figure 1: Mice race used in experiments

\section{Devices and Chemical substance}

Anesthetic with the rate of ketamin:xylazine:water is 3:3:4;

Formalin 10\%;

Hair removal cream;

Rubbing alcohol. 


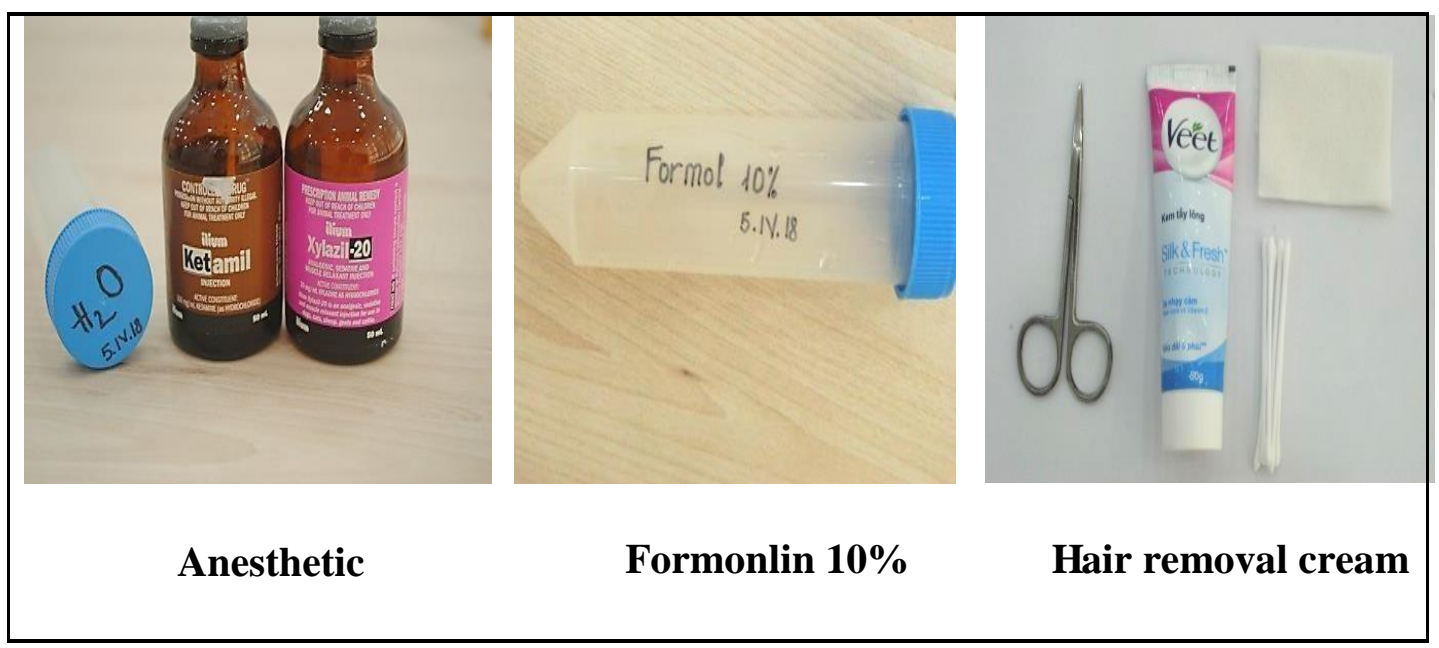

Figure 2: Chemicals used in the experiment

Thermal camera FLIR Lepton: showing the temperature of the wound Camera Nikon D3000: showing the Picture with naked eyes

Pasma devices

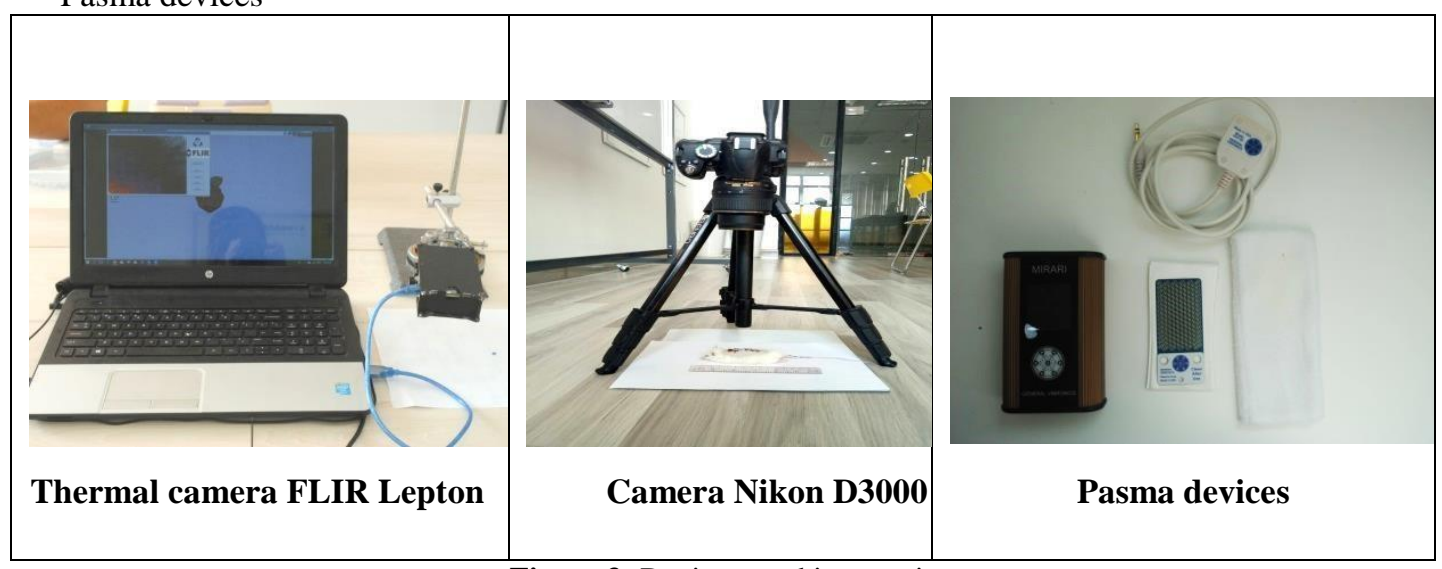

Figure 3: Devices used in experiment

Software for Data processing

Orgin: to show the skin struture and draw charts.

Matlab: to localize the burn area

Images J: to process pictures taken by Nikon, calculate burn area.

Experiment

Making the third degree thermal burn in mice.

Healing skin burn process is compared and evaluated that by making the same skin burn on one mice's back. NT: without treatment; P: with plasma treatment. Treatment process happended in on first five days (two days: antibacterian/anti-imflammatory; three days: epitheliogenetic period ). Durring this process, skin burn areas were taken photo by Canon 3000 Camera, Thermal Camera. Results was monitored and collected everyday. The skin burn areas were cut as sample and undergo HE staining at 
Healing the third degree thermal burn in mice by Dielectric Barrier Discharge Plasma: ... Ngo et al.

first day, seventh day and fourteenth day. Since the sixth day, two skin burn areas did no receive any treatment and continuesly being monitored and evaluated by normal images and thermal images. Average burn area: $167.1 \mathrm{~mm} 2$, temperaute: about 65 degress, time : 15 seconds.

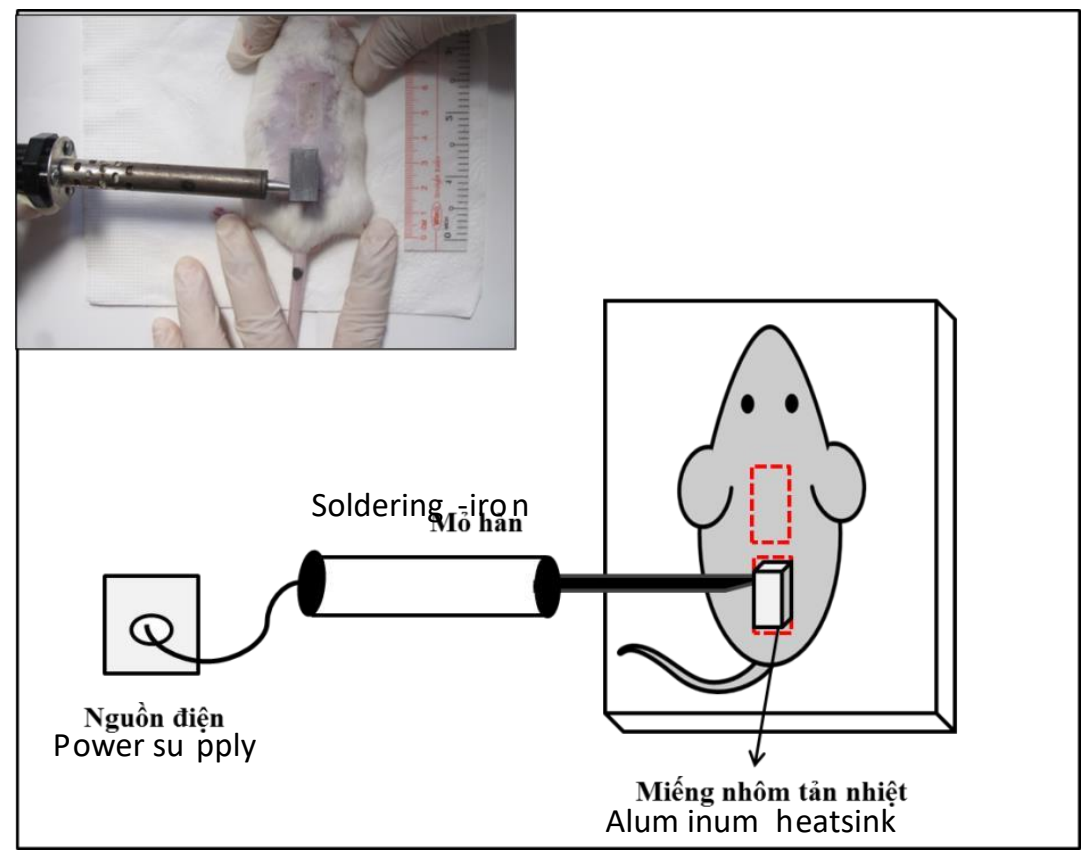

Figure 4: Making the third degree thermal burn in mice.

\section{HE staining}

Show the structure of cell ( nucleus, cytohyaloplasm) and tissue ( collagen) and that can respond the demand for diagnosing diseased at mall - scale (microsurgey). Because the tissues do not contrast with optical microscope or electronic microscope so HE staining can make the diseased tissue stand out.

\section{Results}

The first day: two burn areas could clearly be seen and do not have the difference.

The third day: two burn areas had a slight difference. While the skin in $\mathrm{P}$ area was shrunk, exfoliated and had dark color; the skin in NT area had the light color and had not shrink. So that the inflammation process of $\mathrm{P}$ area happened faster and stronger than NT area.

The seventh day: the exfoliated skin was appeared on two areas due to the fact that the recovery became to epitheliogenetic period but this one in $\mathrm{P}$ area was dry and had more.

The tenth day: epitheliogenetic period were continue, the skin in P area exfoliated and shrunk faster but this one in NT area did not exfoliate.

The fourteenth day: the skin in NT area was dry but did not exfoliate. In contrast, the skin in P area was dry and became nearly normal.

The twenty first day: the skin in NT area not shrunk complety, had the dark color and changed in the negative way. On the other hand, the skin in P area shrunk completely, had light color and was considered that had the recovery period happend fast. 
Healing the third degree thermal burn in mice by Dielectric Barrier Discharge Plasma: ... Ngo et al.

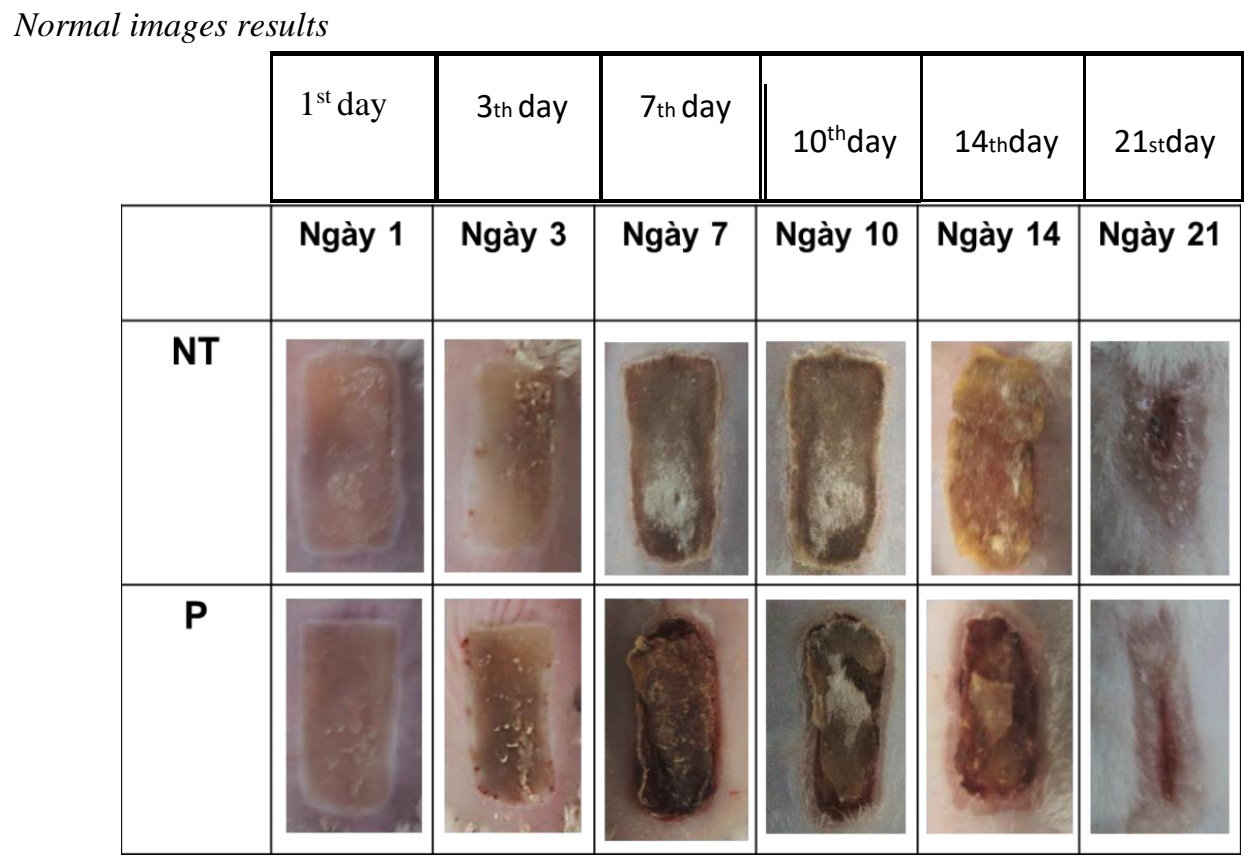

Figure 5: Monitor the shrink of burn area through nomal images measured by the time (NT: non-treatment; P: Plasma treatment).

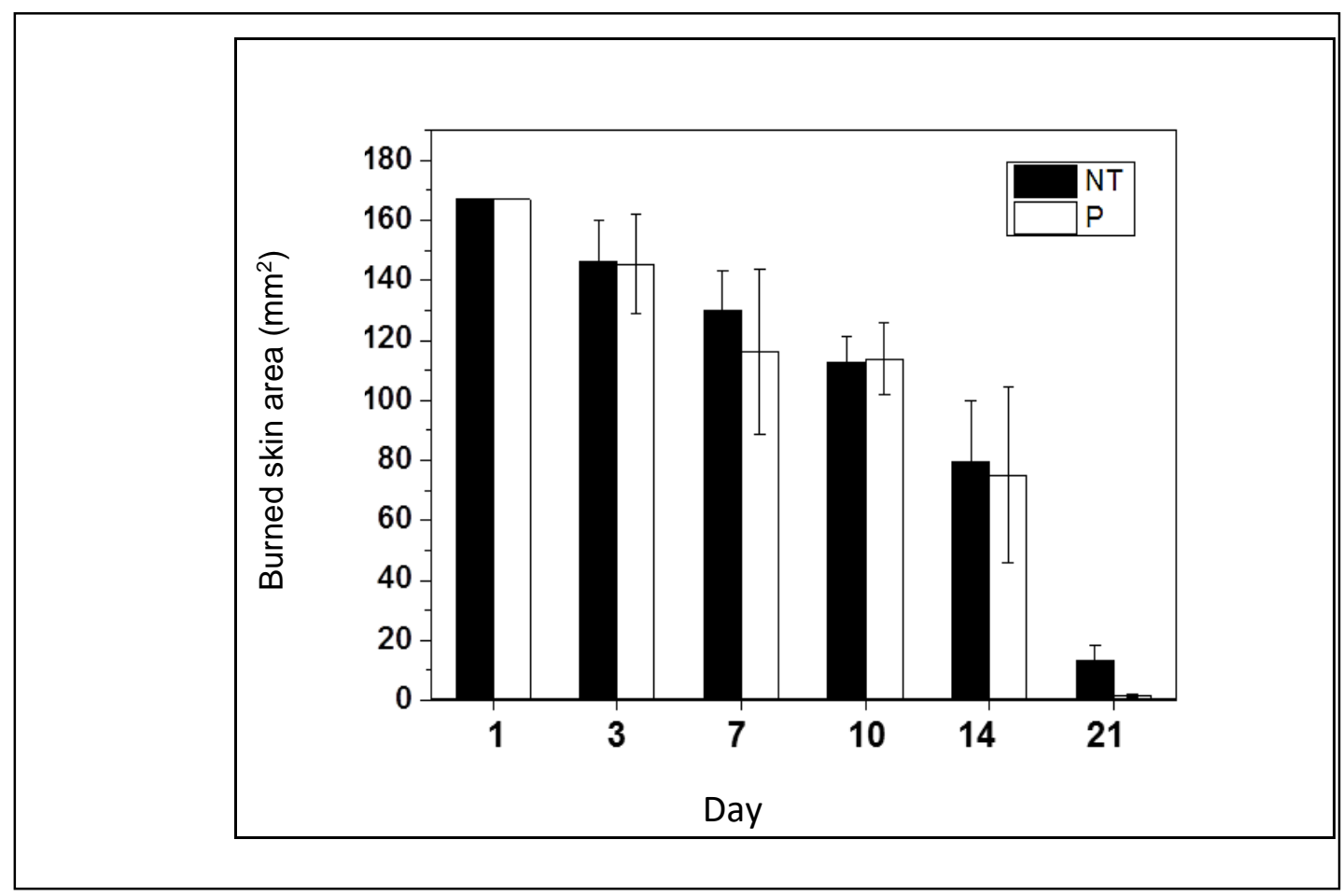

Figure 6: Chart of the shrink of burn area recorded in superficies by the time. 
Healing the third degree thermal burn in mice by Dielectric Barrier Discharge Plasma: ... Ngo et al.

From the first day to the the third day: did not have the difference.

At the seventh day, fourteenth day anf twenty first day: the skin in $\mathrm{P}$ area shrunk faster than this one in NT area.

At the tenth day: because the inflammation process of $\mathrm{P}$ area happened faster and stronger than NT area so that the P area was lightly higher than NT one.

Thermal results
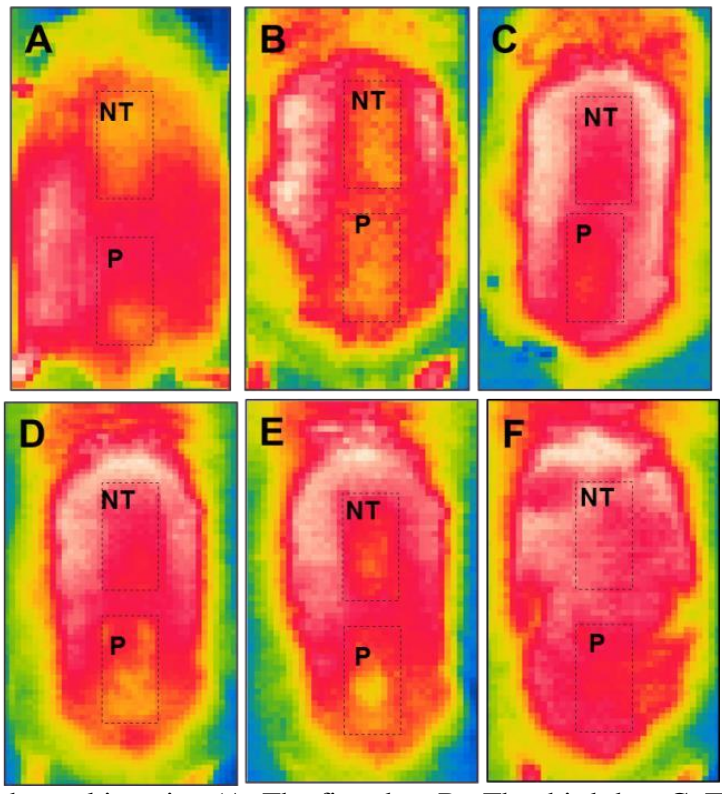

Figure 7: Unprocessed thermal imaging (A. The first day; B. The third day; C. The seventh day; D. The tenth day; E. The fourteenth day; F. The twenty first day)

Based on the thermal images which not being processed, the difference is hard to find. Howerver, at the frist day, the tenth day and fourteen day had a sight difference: the red color in NT area was darker than this one in $\mathrm{P}$ area.

HE staining results: comparison and evaluation of area, burn wound healing time.

a) NT-7 ngày

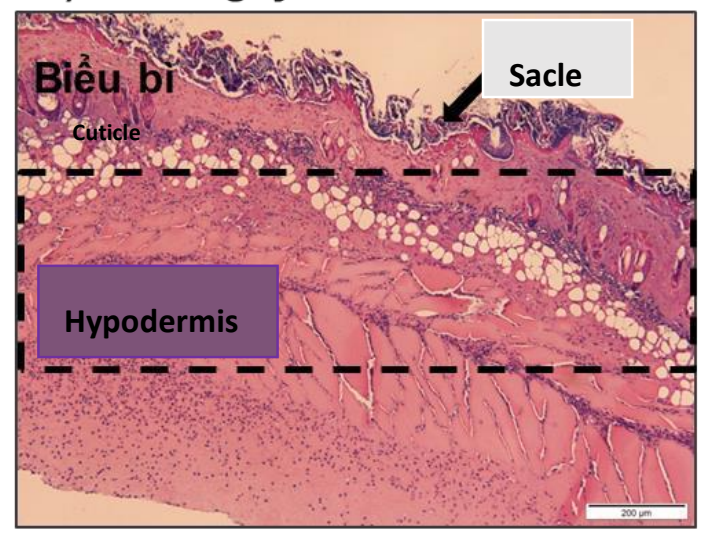

b) P-7 ngày

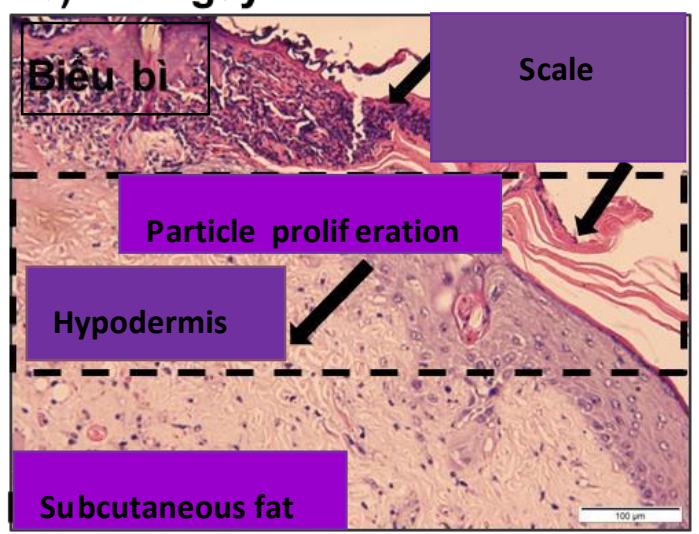

Figure 8: Images results taken by microscope at the seventh day the skin burn NT area (a) and the skin burn P abrea (b) 
Healing the third degree thermal burn in mice by Dielectric Barrier Discharge Plasma: ... Ngo et al.

The skin in NT ( the figure 8 a): area was in the inflammation process; exfoliated skin was sharped and the outline was dry.

The skin in $\mathrm{P}$ area ( the figure $8 \mathrm{~b}$ ): the exfoliated skin is nearly disappered, scarf-kin was got smaller and this area shurnk faster.

\section{Conclusion}

By camera, this study show that the speed of shrinking in P area are faster than NT area. Athought the difference between two methods not clearly be seen but it can show the fact that using plasma treatment is the new way in treatting third degree thermal burn as well burn area.

Experimental results are compared with two evaluation methods: thermal images and HE staining, two targets about temperature and healing time. This is an important step because just making conclusion through normal images that is so subjective. By naked eyes, the results show that the surface of skin without treatment have a wide exfoliated skin than the one with plasma treatment but the thermal images prove the opposite. Moreover, using HE staining at the small - scale ( struture of burn skin area) confirm the correctness of the results. Finally, for the reasons mentioned above, the research show that the burn skin area with plasma treatment are more effective than the one without treament through. The speed of shrinking suface is faster around 5\%; Healing time is faster about 2 to 3 days; Average temperature of burn area is lower approxiamtely 1 to 2 degree.

\section{Acknowledgment}

This research is funded by Ho Chi Minh city University of Technology - HCMC under grant number SVCQ-2018-KHUD-105.

\section{Conflict of interest statement}

The authors declare that they have no conflict of interest.

\section{References}

D. Herndon, "Prevention of Burn Injuries," in Total Burn Care, 4th ed., vol. 1., Ed. Edinburgh: Elsevier Saunders, Ch. 4, pp. 28-35, 2007.

R. Gomez et al., "Causes of mortality by autopsy findings of combat casualties and civilian patients admitted to a burn unit," (in E), J Am Coll Surg, vol. 208, no. 3, pp. 348-54, Mar 2009.

M. P. Rowan et al., "Burn wound healing and treatment: review and advancements," (in E), Crit Care, vol. 19, p. 243, Jun 122015.

M. D. Peck, "Edidemiology of burns throughout the world. Part I: Distribution and rist factors," (in E), Burns, vol.37, no.7 pp. 1087-100, Nov 2011.

B. A. Latenser et al., " National Burn Repository 2006: a ten-year review," (in E), J Burn Care Res, vol. 28, no. 5, pp. 635-58, Sep-Oct 2007.

N.Le. "Báo cáo tổng quan Bỏng Việt Nam," presented at Hội nghị Khoa học bỏng, phẫu thuật tạo hình và liền vết thương toàn quốc lần thứ XII, Đà Nẵng, 2017. 